\title{
Tertiary skipped diynes: a pluripotent building block for the modular and diversity-oriented synthesis of nitrogen heterocycles
}

\author{
David Tejedor, ${ }^{*[a],[b]}$ Sara López-Tosco, ${ }^{[a],[b]}$ Javier González-Platas ${ }^{[c]}$ and Fernando García- \\ Tellado*,[a],[b]
}

The development of diversity-oriented synthetic methodologies (DOS) to construct libraries of small molecules to explore the chemical space is a current topic in modern organic synthesis. ${ }^{[1]}$ An important challenge of these methodologies is the generation of skeletal diversity. This can be generated using the so-called reagent-based DOS methodology which utilizes different reagents to transform a substrate into an array of products having distinct molecular skeletons. ${ }^{[2]}$ In practice, two main reagent-based strategies are currently used: The densely functionalized molecule (different functionalities at the same molecule are sequentially transformed by different reagents) and the pluripotent functional group (a same functional group at the molecule is transformed by

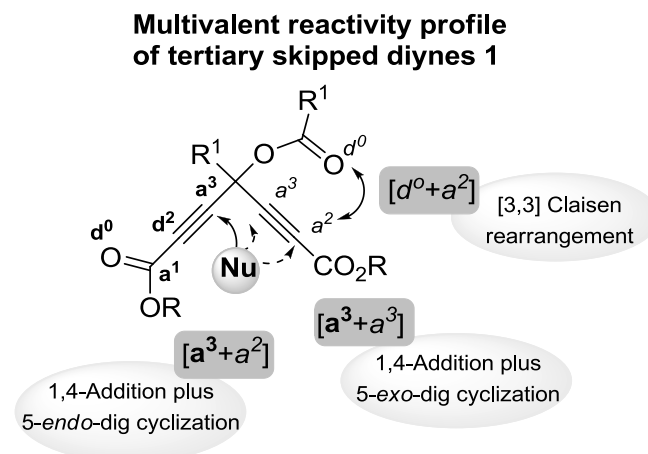

Figure 1. Reactivity profile of tertiary skipped diynes $\mathbf{1}$.

[a] Dr. D. Tejedor, S. López-Tosco, Dr. F. García-Tellado Department of Química Biológica y Biotecnología Instituto de Productos Naturales y Agrobiología Consejo Superior de Investigaciones Científicas Astrofísico Francisco Sánchez 3 38206 La Laguna, Tenerife, Spain Fax: (+)34922-260135

E-mail: fgarcia@ipna.csic.es; dtejedor@ipna.csic.es http://www.ipna.csic.es/departamentos/qbb/qb/

[b] Dr. D. Tejedor, S. López-Tosco, Dr. F. García-Tellado Instituto Canario de Investigación del Cáncer, http://www.icic.es

[c] Dr. J. González-Platas (Crystallographer) Servicio de Difracción de Rayos X Departamento de Física Fundamental II Universidad de La Laguna

Avda. Astrofísico Francisco Sánchez 2, 38204 La Laguna, Tenerife, Spain. different reagents in different reactions). ${ }^{[3]}$ The latter approach requires the use of building blocks bearing a functional group or an array of interconnected functional groups featuring a polyvalent reactivity profile. Skipped diynes $1^{[4]}$ bearing a quaternary $\mathrm{sp}^{3}$-center and two conjugated alkyne units constitute an example of such building blocks (Figure 1) $\left(\mathbf{a}^{\mathbf{i}} / \mathbf{d}^{\mathbf{i}}\right.$ refers to acceptor/donor properties of position i).$^{[5]}$ A recent report from this lab has shown that these diynes are efficient precursors of chain functionalized tetrasubstituted pyrroles $\mathbf{2}$ via an efficient microwave assisted domino reaction with primary amines (Scheme 1). ${ }^{[6]}$ The necessary pyrrole connectivity is generated from the enamine intermediate I via a selective 5-endo-dig cyclization reaction ( $a^{2}$ reactivity; anti-aza-Michael addition) in the form of a transient pyrrolidine intermediate II which rearranges to the final pyrrole 2 via a sigmatropic [3,3]-Claisen rearrangement $\left(\left[d^{0}+a^{2}\right]\right.$ reactivity). In this communication we report our preliminary results in the use of this $\mathrm{C}_{7}$ pluripotent array of organic functionalities for the generation of other important N-containing heterocycles. As a proof of concept, we describe herein a convenient approach to the regioselective

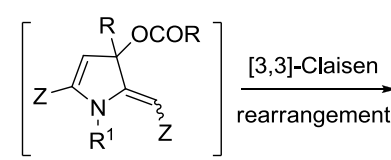

Transient intermediate II

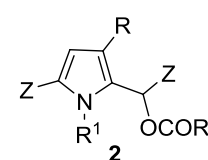<smiles>[Z]C=C1NC([R])C([R])N/C(=C\[Z])C1([R])O[R]O[R]</smiles>

Enamine intermediate I

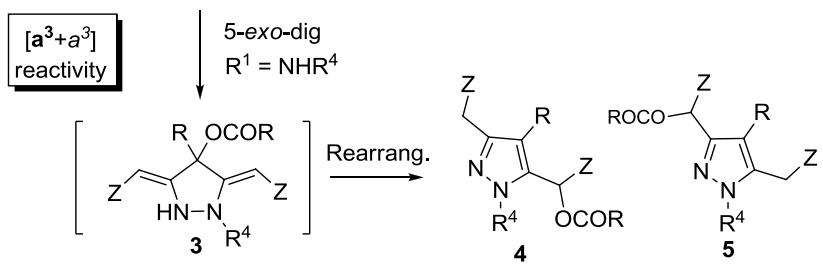

Scheme 1.Pluripotent functional array approach to the DOS synthesis of pyrroles 2 pyrazoles 4 and 1,4-diazepanes 6 from tertiary skipped diynes $1 . Z=\mathrm{CO}_{2} \mathrm{R}^{5}$ 
domino synthesis of chain functionalized fully substituted pyrazoles 4 using $N$-substituted hydrazine derivatives $\left(\mathrm{R}^{2} \mathrm{NHNH}_{2}\right)$ as nucleophiles (Scheme 1). As an extension of this concept, we have also synthesized 1,4-diazepane derivatives 6 by the use of ethane-1,2-diamine derivatives as $\mathrm{N}$-centered nucleophiles (Scheme 1).

We first focused our efforts on pyrazoles because these heterocycles constitute an important structural motif ${ }^{[7]}$ present in a large number of bioactive molecules spanning a large array of biological and pharmaceutical properties. ${ }^{[8]}$ Traditionally, these heterocyclic units have been assembled by condensation reactions of 1,3-dicarbonyl compounds and hydrazines, ${ }^{[9]}$ or by cycloaddition reactions between alkynes and electron-rich diazo compounds. ${ }^{[10]}$ However, regioselectivity has been a recurrent problem with many of these reactions. In recent years, efficient new processes involving alkyne-containing materials have emerged. These include, among others, $\mathrm{Cu}$-catalyzed domino $\mathrm{C}-$ $\mathrm{N}$ coupling/hydroamidations, ${ }^{[1]}$ hydrohydrazinations ${ }^{[12]}$ and azacyclizations of elaborated substrates. ${ }^{[13]}$ In spite of these advances, the development of general and highly efficient domino metalfree methodologies for the regioselective access to polysubstituted pyrazoles in a modular and diversity-oriented manner from easily accessible starting materials remains a challenge. ${ }^{[14,15]}$

We initiated our studies with the reaction of commercially available $N$-methyl hydrazine (7a) (1.1 equiv) and skipped diyne 1a (1 equiv) under different experimental conditions [Eq. (1); Table 1). We were pleasant to observe that the microwave irradiation of a solution of $\mathbf{7 a}$ and $\mathbf{1 a}$ in tert-butanol (technical grade; 100 watt, $100{ }^{\circ} \mathrm{C}$, closed vessel) delivered pyrazole 4aa in short time and excellent yield (30 min, 92\%) (entry 5) accompanied with a small amount (4\%) of the solvolysis product (Solv.; $\mathrm{R}=t \mathrm{BuO}$ ). Other assayed conditions also afforded product 4aa but with lower efficiency and/or longer reaction times (entries $1-8)$.

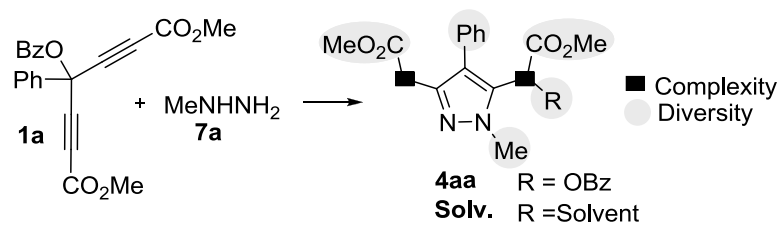

Table 1. Reaction of skipped diyne 1a and hydrazine 7a.

\begin{tabular}{cccccc}
\hline & Solvent & $\Delta / \mathrm{MW}^{[\mathrm{a}]}$ & Time & 4aa (\%) & Solv. (\%) \\
\hline 1 & $\mathrm{ClCH}_{2} \mathrm{CH}_{2} \mathrm{Cl}$ & Reflux & $4 \mathrm{~h}$ & 77 & -- \\
2 & $\mathrm{ClCH}_{2} \mathrm{CH}_{2} \mathrm{Cl}$ & $\mathrm{MW}$ & $30 \mathrm{~min}$ & 79 & -- \\
3 & $\mathrm{EtOH}$ & Reflux & $4 \mathrm{~h}$ & 87 & 14 \\
4 & $i \mathrm{PrOH}$ & Reflux & $4 \mathrm{~h}$ & 91 & 8 \\
5 & $t \mathrm{BuOH}$ & Reflux & $8 \mathrm{~h}$ & 88 & $\mathrm{nd}^{[\mathrm{b}]}$ \\
5 & $t \mathrm{BuOH}$ & $\mathrm{MW}$ & $30 \mathrm{~min}$ & 92 & 4 \\
6 & “ & $\mathrm{MW}$ & 15 min & 81 & $\mathrm{nd}^{[\mathrm{b}]}$ \\
7 & “ & $\mathrm{MW}$ & $1 \mathrm{~h}$ & 91 & 3 \\
8 & $\mathrm{~F}_{3} \mathrm{CCH}_{2} \mathrm{OH}$ & $\mathrm{MW}$ & $30 \mathrm{~min}$ & 86 & 8 \\
\hline
\end{tabular}

[a] Microwave irradiation: 100 watt, $100^{\circ} \mathrm{C}$, closed vessel.[b] Not detected

Four chemical properties of this reaction deserve to be highlighted: 1) efficiency: the domino reaction constructs the pyrazole topology placing a different substituent at each available ring position, in excellent yield and under bench-friendly conditions; 2) regioselectivity: pyrazole $\mathbf{4 a a}$ is obtained as the only regioisomer (pyrazole $\mathbf{5}$ is not detected)(see ESI for details); 3) chemoselectivity: products coming either from the double attack of the same nitrogen atom on the diyne system (5-endo-dig cyclization ${ }^{[6]}$ or from a cyclocondensation reaction between the hydrazine and just one of the two acetylenic esters present in the skipped diyne ${ }^{[16]}$ are not observed and 4) diversity/complexity: pyrazoles are assembled bearing five points of diversity and one $\alpha$-acyloxy ester chain placed in the ortho-position to the substituted $\mathrm{N}$-atom of the ring. This arrangement should allow the development of selective complexity generating reactions involving both functionalities (e.g., ring formation).

Once the reaction could be standardized, we next studied the scope of this domino reaction with regard to the hydrazine and the diyne (Table 2). In general, the reaction displayed a wide scope with regard to both components. Although the reaction was tolerant with the nature of the substituent at the hydrazine nitrogen, it was observed that aliphatic substituents afforded the corresponding pyrazoles $\mathbf{4}$ in better yields than the aromatic ones (compare entries 1,3-6 with 2, 8, 9). Whereas $N$-(4-bromophenyl)hydrazine (7h) gave the corresponding pyrazole $4 \mathbf{a h}$ in modest yield (47\%, entry 8$), \mathrm{N}$-phenylhydrazine (7b) and the electronrich substituted hydrazine $\mathbf{7 i}$ afforded the corresponding pyrazoles 4ab and 4ai in good yields (80\% and 74\%)(entries 2 and 9). Conversely, hydrazines bearing electron-poor aromatic rings $\left(p \mathrm{CF}_{3}-\mathrm{C}_{6} \mathrm{H}_{4} \mathrm{NNH}_{2}\right.$ and $p \mathrm{NO}_{2}-\mathrm{C}_{6} \mathrm{H}_{4} \mathrm{NNH}_{2}$ ) or a sulphonate group $\left(\mathrm{TsNNH}_{2}\right)$ were not reactive enough to participate in this reaction (data not shown). Hydrazines $\mathbf{7 d}$ and $\mathbf{7 e}$ featuring a reactive functionality at the end of the alkyl chain reacted with diyne $\mathbf{1 a}$ in a very chemoselective and efficient manner to yield pyrazoles $\mathbf{4 a d}$

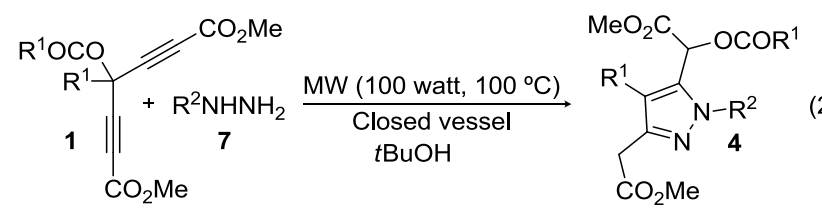

Table 2. Microwave-assisted synthesis of pyrazoles $4 .^{[\mathrm{a}]}$

\begin{tabular}{|c|c|c|c|c|c|c|c|}
\hline & $\mathrm{R}^{1}$ & & $\overline{\mathrm{R}^{2}}$ & & $\mathrm{t}(\min )$ & \multicolumn{2}{|c|}{$4(\%)$} \\
\hline 1 & $\mathrm{Ph}$ & $1 \mathrm{a}$ & $\mathrm{Me}$ & $7 \mathrm{a}$ & 30 & $4 \mathrm{aa}$ & 92 \\
\hline 2 & “ & “ & $\mathrm{Ph}$ & $7 b$ & 45 & $4 \mathrm{ab}$ & 80 \\
\hline 3 & “ & “ & $\mathrm{Bn}^{[\mathrm{b}]}$ & $7 \mathrm{c}$ & 60 & $4 \mathrm{ac}$ & 80 \\
\hline 4 & “ & “ & $\mathrm{NCCH}_{2} \mathrm{CH}_{2}$ & $7 d$ & 30 & $4 \mathrm{ad}$ & 73 \\
\hline 5 & “ & “ & $\mathrm{HOCH}_{2} \mathrm{CH}_{2}$ & $7 \mathrm{e}$ & 30 & $4 \mathrm{ae}$ & 75 \\
\hline 6 & “ & “ & $c \mathrm{Hex}^{[\mathrm{b}]}$ & $7 f$ & 30 & $4 \mathrm{ae}$ & 85 \\
\hline 7 & “ & “ & $\mathrm{H}^{[\mathrm{c}]}$ & $7 \mathrm{~g}$ & 30 & $4 a g$ & 63 \\
\hline 8 & “ & “ & $4-\mathrm{BrC}_{6} \mathrm{H}_{4}{ }^{[\mathrm{b}]}$ & $7 \mathrm{~h}$ & 180 & $4 \mathrm{ah}$ & 47 \\
\hline 9 & “ & “ & $4-\mathrm{MeOC}_{6} \mathrm{H}_{4}{ }^{[\mathrm{b}]}$ & $7 \mathrm{i}$ & 45 & 4ai & 74 \\
\hline 10 & $p \mathrm{ClC}_{6} \mathrm{H}_{4}$ & $1 b$ & $\mathrm{Me}$ & $7 a$ & 30 & $4 \mathrm{ba}$ & 95 \\
\hline 11 & $p$ Tolyl & $1 \mathrm{c}$ & “" & “ & 30 & $4 \mathrm{ca}$ & 99 \\
\hline 12 & $p$ Biphenyl & $1 d$ & “" & “ & 30 & $4 \mathrm{da}$ & 90 \\
\hline 13 & $p \mathrm{MeOC}_{6} \mathrm{H}_{4}$ & $1 \mathrm{e}$ & “ & “ & 30 & 4ea & 97 \\
\hline 14 & $o \mathrm{ClC}_{6} \mathrm{H}_{4}$ & $1 \mathrm{f}$ & “ & “ & 30 & $4 \mathrm{fa}$ & 88 \\
\hline 15 & $i \operatorname{Pr}$ & $1 \mathrm{~g}$ & “ & “ & $60^{[\mathrm{d}]}$ & $4 \mathrm{ga}$ & 95 \\
\hline 16 & $c \mathrm{Hex}$ & $1 \mathrm{~h}$ & “ & “ & $60^{[\mathrm{d}]}$ & 4ha & 97 \\
\hline
\end{tabular}

[a] Diyne $(0.5 \mathrm{mmol})$, hydrazine $(0.55 \mathrm{mmol}), t \mathrm{BuOH}(5 \mathrm{~mL}), \mathrm{MW}$ (100 watt, $100^{\circ} \mathrm{C}$ ), closed vessel. [b] Hydrazine was used in the form of its hydrochloride salt. Reaction was performed in the presence of NaOAc (3.3 eq). [c] $1.0 \mathrm{M}$ in THF. [d] 300 watt; $150{ }^{\circ} \mathrm{C}$. 
and 4ae in very good yields, with the extra functionality untouched (entries 4 and 5). These extra functionalities could be convenient handles for further generation of molecular complexity. Remarkably, simple hydrazine $\mathbf{7 g}$ reacted with diyne 1a in a very efficiently manner to construct the trisubstituted pyrazole 4ag in good yield (63\%, entry 7). The diyne scope was studied using $N$-methylhydrazine $7 \mathbf{a}$ and a set of different substituted tertiary skipped diynes 1a-h (entries 10-16). In general, the reaction was tolerant with the nature of the substituent at the tertiary $\mathrm{sp}^{3}$-center. Although both aliphatic and aromatic derivatives generated the corresponding pyrazoles in excellent yields, aliphatic derivatives needed more energetic conditions than their aromatic homologues to deliver the corresponding pyrazoles in good yields (compare entries 10-14 with 15 and 16).

With regard to the mechanism of this domino reaction, a proposal is outlined in Scheme 2. Remarkably, the advanced intermediate III could be isolated when reactions were performed at room temperature. Further transformation of this ring into pyrazole 4 via a [3,3]-Claisen rearrangement required heating (microwave activation) to proceed in a reasonable time (See ESI for details). As expected, this transformation constitutes the rate determining step of the domino process.

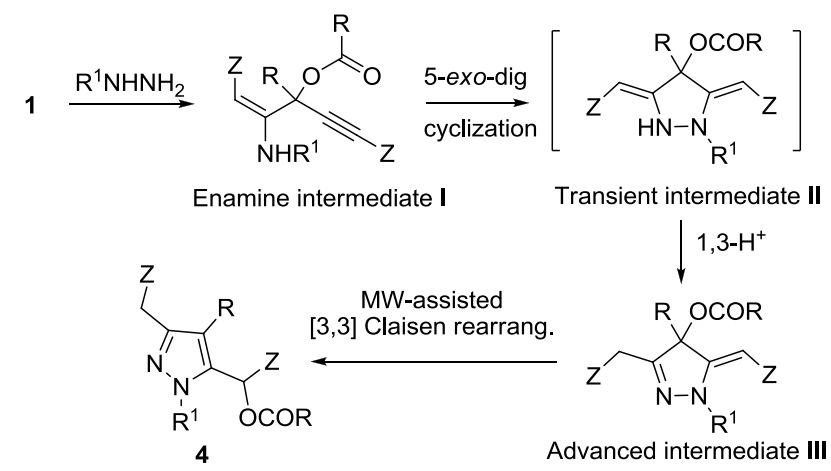

Scheme 2. Mechanistic proposal for the synthesis of pyrazoles 4. $\mathrm{Z}=\mathrm{CO}_{2} \mathrm{R}^{2}$

It should be noted that the final [3,3]-Claisen rearrangement distinguishes the two ester functionalities by placing an oxygen functionality in the alpha position to one of them. This electronically differentiated ester group should be expected to hydrolyze easier and faster than the other ester group. Hence, the controlled hydrolysis of pyrazole derivative $4 \mathbf{a a}\left(\mathrm{LiOH}, \mathrm{THF} / \mathrm{H}_{2} \mathrm{O}\right.$, $0^{\circ} \mathrm{C}$, 6h) [Eq. (3)] proved to be chemoselective, generating monoacid $\mathbf{8}$ in good yield (72\%)(See ESI for details). The free carboxylic acid function at pyrazole $\mathbf{8}$ gives rise to another point for diversity and/or complexity generation (it can be used as a convenient chemical handle)
Once the transformation of skipped diynes $\mathbf{1}$ into pyrazoles was successfully achieved, we next studied the reaction of these diynes with other diamines to gain access to different $\mathrm{N}$ heterocycles. Thus, the reaction of diyne 1a with 1,2-substituted ethane-1,2-diamines 9a-c afforded 1,4-diazepane derivatives 6a-c in good yields and stereoselectivity $\left(Z, Z\right.$-isomer) ${ }^{[17]}$ (See ESI for details), via two consecutive and energetically favoured azaMichael additions, the latter being a 7-exo-dig cyclization process (Scheme 3). The 1,4-diazepane core ${ }^{[18]}$ constitutes a biological valuable scaffold ${ }^{[19]}$ with interesting applications as surrogate of the biologically relevant piperazine ring (homopiperazines). ${ }^{[20]}$ Surprisingly, benzene-1,2-diamine (9d) featuring two aromatic amines did not give the corresponding bicyclic 1,4-diazepane $\mathbf{6 d}$, affording an unresolved mixture of unidentified compounds. Remarkably, the reaction of propane-1,3-diamine (10a) with diyne 1a under these conditions did not afford the corresponding 1,5-diazocane 11a, but it generated the $N$-substituted pyrrole 12a (12\%; not optimized yield). This result mirrors the inherent energy differences between 5-endo-dig (favoured) and 8-exo-dig (unfavoured) cyclizations. A similar result was obtained when butane-1,4-diamine $(\mathbf{1 0 b})$ was reacted with diyne 1a under the same reaction conditions (Scheme 3). Instead of the expected 1,5diazonane derivative $\mathbf{1 1 b}$ resulting from an allowed 9-exo-dig cyclization process, pyrrol 12b was obtained as the major compound (21\%; not optimized yield). These studies show that the length of the alkyl chain of the diamine determines the fate of the cyclization reaction, and therefore the outcome of the process. Only 1,2-diamines react with diyne 1a using their two nitrogen atoms to afford 1,4-diazepane derivatives $\mathbf{6}$ via two kinetically allowed aza-Michael additions. The rest of the 1,n-diamines react as simple monoamines affording the corresponding $\mathrm{N}$ (aminoalkyl)-pyrrole derivatives 12 via a well established domino mechanism. $^{[6]}$
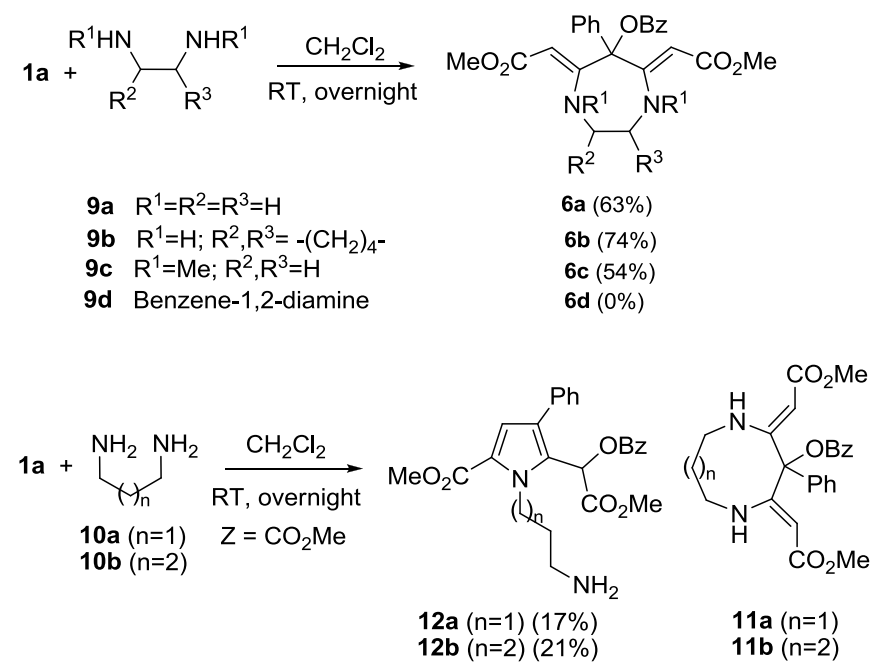

Scheme 3. Reaction of skipped diyne 1a and alkane 1,n-diamines.

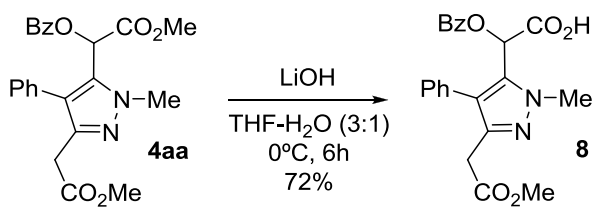




\section{Experimental Section}

Representative procedure for the microwave-assisted synthesis of pyrazoles (4aa-4ha). Methylhydrazine 7a $(0.55 \mathrm{mmol})$ was added to a solution of diyne 1a $(0.50 \mathrm{mmol})$ in $t$-Butanol $(4 \mathrm{ml})$. The reaction mixture was placed in a microwavespecial closed vial and the solution was irradiated for $30 \mathrm{~min}$ in a single-mode microwave oven $\left(100 \mathrm{Watt}, 100{ }^{\circ} \mathrm{C}\right)$. After removing the solvent at reduced pressure the products were purified by flash column chromatography (silica gel, nhexane/EtOAc 40/60) to yield 4aa $(92 \%) .{ }^{1} \mathrm{H}$ NMR $\left(400 \mathrm{MHz}, \mathrm{CDCl}_{3}, 25^{\circ} \mathrm{C}\right): \delta=$ $3.61(\mathrm{~d}, 1 \mathrm{H}, J=16.9 \mathrm{~Hz}), 3.63(\mathrm{~s}, 3 \mathrm{H}), 3.66\left(\mathrm{~d},{ }^{3} J(\mathrm{H}, \mathrm{H})=16.4 \mathrm{~Hz}, 1 \mathrm{H}\right), 3.71(\mathrm{~s}, 3 \mathrm{H})$, $4.04(\mathrm{~s}, 3 \mathrm{H}), 6.38(\mathrm{~s}, 1 \mathrm{H}), 7.32-7.45(\mathrm{~m}, 7 \mathrm{H}), 7.55-7.60(\mathrm{~m}, 1 \mathrm{H}), 7.99\left(\mathrm{~d},{ }^{3} \mathrm{~J}(\mathrm{H}, \mathrm{H})=\right.$ $7.2 \mathrm{~Hz}, 2 \mathrm{H}) \mathrm{ppm} ;{ }^{13} \mathrm{C}$ NMR $\left(100 \mathrm{MHz}, \mathrm{CDCl}_{3}, 25^{\circ} \mathrm{C}\right): \delta=32.5,38.0,52.0,53.0$, $65.5,123.7,127.6,128.5,128.6,128.7,129.9,130.0,131.3,132.4,133.7,142.7$, $165.0,167.2,171.0 \mathrm{ppm}$; IR $\left(\mathrm{CHCl}_{3}\right): \mathrm{v}=3000.3,3028.2,2955.9,1733.3,1445.8$, 1334.9, 1266.5, $1237.71175 .0,1099.0 \mathrm{~cm}^{-1}$; MS (70 eV): $\mathrm{m} / z(\%): 422$ (30) $[\mathrm{M}+]$, 317 (20), 259 (6.3), 241 (11), 105 (100), 77 (15); elemental analysis calcd (\%) for $\mathrm{C}_{23} \mathrm{H}_{22} \mathrm{~N}_{2} \mathrm{O}_{6}$ : C 65.39, H 5.25, N 6.63; found: C 65.38, H 5.28, N 6.43.

Representative procedure for the synthesis of diazepanes (6a-6c). Ethane-1,2diamine $(0.55 \mathrm{mmol})$ was added to a solution of diyne $1 \mathrm{a}(0.5 \mathrm{mmol})$ in dry $\mathrm{CH}_{2} \mathrm{Cl}_{2}$ $(13 \mathrm{ml})$ at room temperature. The reaction mixture was stirred overnight. After removing the solvent at reduced pressure the products were purified by flash column chromatography (silica gel, EtOAc / $\mathrm{CH}_{2} \mathrm{Cl}_{2}$ 10/90) to yield 6a (63\%). mp 199.3$199.6^{\circ} \mathrm{C} .{ }^{1} \mathrm{H}$ NMR $\left(400 \mathrm{MHz}, \mathrm{CDCl}_{3}, 25^{\circ} \mathrm{C}\right): \delta=3.53(\mathrm{~s}, 6 \mathrm{H}), 3.57-3.62(\mathrm{~m}, 2 \mathrm{H})$, 3.69-3.74 (m, 2H), $4.87(\mathrm{~s}, 2 \mathrm{H}), 7.33-7.39(\mathrm{~m}, 3 \mathrm{H}), 7.47-7.51(\mathrm{~m}, 2 \mathrm{H}), 7.61(\mathrm{tt}$, $\left.{ }^{3} J(\mathrm{H}, \mathrm{H})=7.4,1.3 \mathrm{~Hz}, 1 \mathrm{H}\right), 7.68-7.70(\mathrm{~m}, 2 \mathrm{H}), 8.09-8.12(\mathrm{~m}, 2 \mathrm{H}), 9.59$ (bs, $\left.2 \mathrm{H}\right)$ $\mathrm{ppm} ;{ }^{13} \mathrm{C}$ NMR $\left(100 \mathrm{MHz}, \mathrm{CDCl}_{3}, 25^{\circ} \mathrm{C}\right): \delta=45.0,50.3,84.1,84.5,126.3,128.3$, $128.65,128.69,129.8,129.9,133.7,141.5,164.3,164.9,171.3 \mathrm{ppm} ; \mathrm{IR}\left(\mathrm{CHCl}_{3}\right)$ : $v=1091.2,1192.8,1262.6,1497.3,1603.8,1655.3,1733.7 \mathrm{~cm}^{-1} ; \mathrm{MS}(70 \mathrm{eV}): \mathrm{m} / z$ (\%): 436 (23) [M+], 331 (63), 315 (50), 283 (37), 105 (100), 77 (35); elemental analysis calcd (\%) for $\mathrm{C}_{24} \mathrm{H}_{24} \mathrm{~N}_{2} \mathrm{O}_{6}$ : C 66.04, $\mathrm{H}$ 5.54, N 6.42; found: C 66.13, H 5.66, N 6.43.

\section{Acknowledgements}

This research was supported by the Spanish Ministerio de Ciencia e Innovación, the European Regional Development Fund (CTQ2008-06806-C02-02) and the Spanish MSC ISCIII (RETICS RD06/0020/1046), FUNCIS (REDESFAC PI01/06 and 35/06) and the Fundación Instituto Canario de Investigación del Cancer (FICIG.I.N808/2007). S. L.-T. thanks Spanish MEC for a FPU grant. Authors thank technician Ms. Anna Jurado Varona for her experimental assistance.

\section{Keywords: alkynes $\bullet$ cyclization $\bullet$ domino reactions $\bullet$ pyrazoles $\bullet 1,4$-diazepanes}

[1] For a review, see: T. E. Nielsen, S. L. Schreiber, Angew. Chem. 2008, 120, 52-61; Angew. Chem. Int. Ed. 2008, 47, 48-56.

[2] M. D. Burke and S. L. Schreiber, Angew. Chem. 2004, 116, 48-60; Angew. Chem. Int. Ed. 2004, 43, 46-58.

[3] For a discussion of this approach see: W. R. J. D. Galloway, A. Bender, M. Welch, D. R. Spring, Chem. Commun. 2009, 2446-2462 and references cited therein

[4] These units are assembled via a tetracomponent $\mathrm{A}_{2} \mathrm{BB}$ ' reaction manifold involving triethylamine, alkyl propiolates and acid chlorides. D. Tejedor, S. López-Tosco, J. González-Platas, F. García-Tellado, J. Org. Chem. 2007, 72, 5454-5456. A 2 BB' means that the component A is incorporated into the final product twice and in the same manner $\left(\mathrm{A}_{2}\right)$ whereas the component $\mathrm{B}$ does it in two chemo-differentiated manners (B and $\mathrm{B}^{\prime}$ ). For a tutorial about these and related multicomponent reactions, see: D. Tejedor, F. García-Tellado, Chem. Soc. Rev. 2007, 36, 484-491.

[5] Each alkynoate group holds a polyvalent reactivity profile which is expressed as simple codes $\mathbf{d}^{\mathbf{0}}, \mathbf{a}^{\mathbf{1}}, \mathbf{a}^{\mathbf{2}}, \mathbf{a}^{\mathbf{3}}, \mathbf{d}^{\mathbf{2}}$ or combinations of them (letters refer to acceptor/donor properties while numbers refer to position). Each notation $\left(\mathbf{a}^{\mathbf{i}}, \mathbf{d}^{\mathbf{i}}\right)$ codifies for a particular chemical transformation at this specific position, i.e., $\mathbf{a}^{\mathbf{1}}$ codifies for 1,2 -addition, $\mathbf{a}^{3}$ for 1,4-addition, and so on. D. Tejedor, S. López-Tosco, F. CruzAcosta, G. Méndez-Abt, F. García-Tellado, Angew. Chem. 2009, 121, 2124-2131; Angew. Chem. Int. Ed. 2009, 48, 2090-2098. For a discussion of this nomenclature, see: D. Seebach Angew. Chem. 1979, 91, 259-278; Angew. Chem. Int. Ed. 1979, 18,239-258 .

[6] D. Tejedor, S. López-Tosco, J. González-Platas, F. García-Tellado, Chem. Eur. J. 2009, 15, 838-842.
[7] Progress in Heterocyclic Chemistry, Vol 18 (Eds.: G. W. Gribble, J. Joule), Elsevier: Oxford, 2007; b) J. Elguero, in Comprehensive Heterocyclic Chemistry II, Vol 3 (Eds.: A. R. Katritzky, C. W. Rees, E. F. V. Scriven), Pergamon: Oxford, 1996.

[8] For the biological relevance of of pyrazoles, see: a) J. Elguero, P. Goya N. Jagerovic, A. M. S. Silva in Targets in Heterocyclic SystemsChemistry and Properties, Vol 6 (Eds.: O. A. Attanasi, D. Spinelli), Italian Society of Chemistry, Rome, 2002.

[9] For selected examples, see: a) A. C. Cuñat, S. Villanova, M. Murguia, J. Org. Chem. 2008, 73, 3523-3529; b) S. T. Heller, S. R. Natarajan, Org. Lett. 2006, 8, 2675-2678; c) Z. Wang and H. Qin, Green Chem. 2004, 6, 90-92; d) A. N. Kost, I. I. Grandberg, Adv. Heterocycl. Chem. 1996, 6, 347- 429.

[10] a) For a review, see: G. W. Gribble, in Synthetic Applications of 1,3Dipolar Cycloaddition toward Heterocycles and Natural Products, (Eds.: A. Padwa, W. H. Pearson), John Wiley \& Sons:New York, 2002, pp. 681-755; for selected recent examples, see: b) D. Vuluga, J. Legros, B. Crousse, D. Bonnet-Delpon, Green Chem. 2009, 11, 156159 and references cited therein; c) X. Qi, J. M. Ready, Angew. Chem. 2007, 119, 3306-3308; Angew. Chem. Int. Ed. 2007, 46, 3242-3244; d) N. Jiang, C. J. Li, Chem. Commun. 2004, 394-395; for selected examples of others 1,3-dipolar cycloadditions: e) K. Harju, J. Vesterinen, J. Yli-Kauhaluoma, Org. Lett. 2009, 11, 2219-2221.

[11] R. Martin, M. R. Rivero, S. L. Buchwald, Angew. Chem. 2006, 118 , 7237-7240; Angew. Chem., Int. Ed. 2006, 45, 7079-7082.

[12] a) K. Alex, A. Tillack, N. Schwarz, M. Belle, Org. Lett. 2008, 10 , 2377-2379; b) B. Willy, T. J. J. Müller, Eur. J. Org. Chem. 2008, 4157-4168; c) for a Pd-catalyzed one-pot four-component construction of pyrazoles, see: M. S. M. Ahmed, K. Kobayashi, A. Mori, Org. Lett. 2005, 7, 4487-4489.

[13] For selected examples, see: a) Z. Chen, X. Yang, J. Wu, Chem Commun. 2009, 3469-3471; b) K. Wang, D. Xiang, J. Liu, W. Pan, D Dong, Org. Lett. 2008, 10, 1691-1694; c) Y. T. Lee, Y. K. Chung, J. Org. Chem. 2008, 73, 4698-4701

[14] For a recent example of metal-free, one-pot regioselective synthesis of polysubstituted pyrazoles from hydrazones and nitroalkenes, see: $\mathrm{X}$. Deng, N. S. Mani, Org. Lett. 2006, 8, 3505-3508.

[15] For a leading example of polyfunctionalization of simple pyrazoles by a multistep protocol, see: C. Despotopoulou, L. Klier, P. Knochel, Org. Lett. 2009, 11, 3326-3329.

[16] The cyclocondensation of alkylhydrazines and $\beta$-substituted acetylenic esters affords 3-hydroxypyrazoles. B. C. Hamper, M. L. Kurtzweil, J. P. Beck, J. Org. Chem. 1992, 57, 5680-5686 and references cited therein.

[17] The 1,4-diazepane structure was unambiguously confirmed by X-ray crystallographic analysis of the derivative $6 \mathbf{b}$. CCDC 759429 contains the supplementary crystallographic data for this compound. These data can be obtained free of charge from The Cambridge Crystallographic Data Centre via www.ccdc.cam.ac.uk/data_request/cif.

[18] For a recent example of stereoselective one-pot access to these structures, see: E. Sotoca, C. Allais, T. Constantieux, J. Rodriguez, Org. Biomol. Chem. 2009, 7, 1911-1920.

[19] T. Tanaka, T. Muto, H. Maruoka, S. Imajo, H. Fukami, Y. Tomimori, Y. Fukuda, T. Nakatsuka, Bioorg. Med. Chem. Lett. 2007, 17, 34313434.

[20] For recent examples, see: a) S. Bedürftig, B. Wünsch, Eur. J. Med Chem. 2009, 44, 519-525; b) L. P. J. Hoeglund, S. Silver, M. T. Engstroem, H. Salo, A.Tauber, H.-K. Kyyroenen, P. Saarenketo, A.-M Hoffren, K. Kokko, K. Pohjanoksa, J. Med. Chem. 2006, 49, 63516363.

Received: ((will be filled in by the editorial staff))

Revised: ((will be filled in by the editorial staff)) Published online: ((will be filled in by the editorial staff)) 
Entry for the Table of Contents (Please choose one layout only)

\section{Layout 1:}

\section{Substrate-based DOS}

David Tejedor, * Sara López-Tosco, Javier González-Platas and Fernando García-Tellado* Page - Page

Tertiary skipped diynes: a pluripotent building block for the modular and diversity-oriented synthesis of nitrogen heterocycles

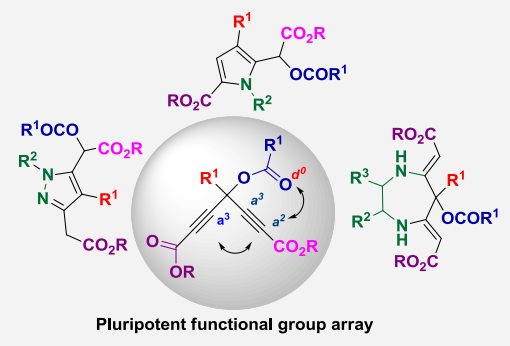

The multivalent reactivity profile of tertiary skipped diynes has been conveniently exploited in the domino and diversity-oriented synthesis of fully substituted pyrazoles and 1,4diazepanes derivatives. The developed manifold is chemically efficient and simple to operate. In addition, the resulting $\mathrm{N}$-containing heterocycles are obtained in a regioand chemoselective manner. 